October - 2003

\title{
Authors' Response
}

\section{To Wim Van Petegem by José Bidarra and Ana Dias}

\author{
José Bidarra \\ Universidade Aberta, Portugal
}

\begin{abstract}
Ana Dias
Interface da Universidade do Minho, Portugal

Editor's Note: This is José Biddara and Ana Dias' response to the review by Wim van Petegem, Katholieke Universiteit Leuven, Belgium. All correspondence between the authors and reviewers, until date of publication, has been blind.
\end{abstract}

It seems to be now established that by adopting non-sequential (hypertext) architecture in texts and introducing therein components of sound, fixed images, and video clips (hypermedia), we have the means of creating new degrees of freedom in the way learning content is approached and studied. Furthermore, we have the potential for including a constructionist or "play" component that may increase its appeal, and facilitate learning, for different learner audiences. We also determine that "mind mapping" is a proven way to elicit knowledge structures in any constructivist learning process. This approach may be connected to different constructivist learning models, for instance, those based on multimedia materials (e.g., Papert's LOGO).

We agree with the first reviewer that Computer Mediated Communication (CMC) has permitted the possibility of assuring student-student interaction through the constitution of discussion and collaborative-learning groups, thus breaking the traditional and awkward isolation of the distance learning student. Online educators have realised that they can generate effective (small) group discussions, if they can provide learners with specific tasks to accomplish. Important aspects are resource quality, scheduling with precise deadlines, and consistent online support. In this regard, the creation of hyperscapes by learners working in virtual groups with access to expert guidance is a good example of socio-constructivism (proposed by Vygotsky for younger learners). Perhaps we did not explain the thought in so many words in the article, but surely, the idea of constructivism is noticeable throughout the text.

We do not think the question to be asked is: "Why should hyperscapes be better than traditional methods?" But rather, we feel we must approach hypermedia as actuality and ask: "How can hyperscapes be integrated with other learning modes (while coping with cognitive variables, pedagogical concerns and multimedia capabilities)" to ensure they address the diversified needs of learners in our sophisticated world? We must bear in mind that in addition to materials specially conceived and produced for use in a given distance learning situation, the Internet now allows students access to a huge amount of supplementary information based on many different 
alternative sources. The challenge remains one of making sure that the information retrieved is positively related to the study subject, and that its source is credible, useful, and relevant for each learner. Surely, this will be the role of the teacher or professor in the years to come.

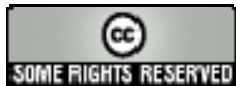

